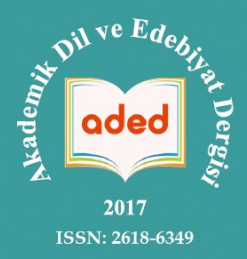

\section{Yakup KARASOY}

Prof. Dr., Ankara Hacı Bayram Veli Üniversitesi

yakup.karasoy@hbv.edu.tr

\section{iD}

https://orcid.org/0000-0002-3856-7489

\section{Akademik Dil ve Edebiyat Dergisi} Journal of Academic Language and Literature PROF. DR. METIN AKAR'A ARMAĞAN (Cilt/Volume: 5, Say1/Issue: 4, Aralık/December 2021)

\author{
Araştırma Makalesi/Research Article \\ Geliş Tarihi/Received: 08.10.2021 \\ Kabul Tarihi/Accepted: 31.10.2021 \\ Yayım Tarihi/Published: 30.12.2021
}

Looking at Another Aspect of "Shiban Khan Divan"

\title{
Atıf/Citation
}

KARASOY, Y. (2021). Şiban Han Dîvâni'na Farklı Bakmak. Akademik Dil ve Edebiyat Dergisi, 5(4), 1688-1697. https://doi.org/10.34083/akaded.1007320

KARASOY, Y. (2021). Looking at Another Aspect of Shiban Khan Divan. Journal of Academic Language and Literature, 5(4), 1688-1697. https://doi.org/10.34083/akaded.1007320

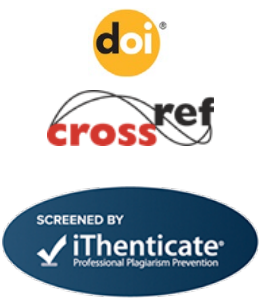

Bu makale iThenticate programıla taranmıştır.

This article was checked by iThenticate. 


\section{Öz}

1451-1510 yılları arasında yaşayan Şiban Han, dedesi Ebu'l Hayr Han'ın ölümünden sonra dağılan Özbek topluluklarını bir araya getirmiştir. Deşt-i Kıpçak’tan güneye inerek Maveraünnehr bölgesini; Harezm, Otrar, Yesi gibi önemli merkezleri ele geçirmiş, Timur Devleti'ne son vererek bölgenin hâkimi konumuna gelmiştir. Şiban Han, tarihî şahsiyetinin yanında şair bir hükümdardır. Eserleri, klasik devir Çağatay Türkçesinin önemli örneklerindendir. Savaş ve mücadelelerle geçen hayatına bir fıkıh risalesi, mürettep bir divan ve Bahru'l-Hüdâ adlı bir manzume sığdırmıştır. Şiirlerinde dönemin tarihî olaylarının ve sosyal hayatının geniş bir yansımasını gözler önüne sermiştir. Bu çalışmada, Şiban Han Dîvânı yalnızca bir dil ve edebiyat ürünü olarak ele alınmamış, farklı bir bakış açısıyla yeniden değerlendirilmeye çalışılmıştır. Şiban Han yönetimindeki Özbek topluluklarının ve bölgede yaşayan diğer Türk ve Moğol boylarının coğrafyasının; doğu ve İslam kültür dairesiyle ilişkili unsurların; savaş ve yönetim stratejileri ile ilgili hususların; başta Babür olmak üzere diğer hükümdar ve yöneticilerle olan çekişmelerin Şiban Han Dîvânı'na yansımaları üzerinde örnekler verilerek durulmuştur.

Anahtar Kelimeler: Sosyal ve kültürel hayat, Şiban Han Dîvânı, Şibaniler

\section{Abstract}

Shiban Khan, who lived in 1451-1510, brought together the Uzbek communities that were dispersed after the death of his grandfather Ebu'l Hayr Khan. Coming down to the south from Deşt-i Kipchak to the Transoxiana region; , he captured important centers such as Khwarezm, Otrar, Yesi, ended the Timurid State, and became the ruler of the region. Shiban Khan is a poet besides his historical personality. His works are notable examples of the classical period of Chagatai Turkish. In his life, which was spent with wars and struggles, he wrote a fiqh treatise, a comprehensive divan and, a poem called Bahru'l-Huda. In his poems, he reveals a wide reflection of the historical events and social life of the period. In this study, Shiban Khan Divan was not only considered as a product of language and literature but also tried to be re-evaluated from a different perspective. The geography of the Uzbek communities under the rule of Shiban Khan and other Turkish and Mongolian tribes living in the region; elements related to the eastern and Islamic cultural circle; issues related to war and management strategies; The reflections of the conflicts with other rulers and administrators, especially with Babur, on the Divan of Shiban Khan are given with examples.

Keywords: social and cultural life, Divan of the Shiban Khan, Shibani period 


\section{Giriş}

Şiban Han, hükümdar bir şairdir. Yazıştığı, savaştığı, görüştüğü, ilişkide bulunduğu bütün hükümdarlar da şairdir.15. yüzyılın son çeyreği ile 16.yüzyılın ilk çeyreğinde izlerini gördügümü̈z Sultan Hüseyin Baykara (1438-1524), Babür Şah (1483-1530), Şah İsmail Hatayî (1487-1524), II.Bayezid (1447-1512) ve Kansu Gavri (1441-1516) yolları bir şekilde Şiban Han (1451-1510) ile kesişmiş hükümdar şairlerdendir. Klasik devir Çağatay Türkçesi şairi Şiban Han, soyunu Cengiz Han’ın büyük oğlu Cuci Han’a (1170-1227) bağlayan, Aral Denizi ve Seyhun'un kuzeyinde yaşayan Özbek topluluklarının güneye, Timurlu ülkesine inmesini sağlayan, Mâverâünnehir'i, Semerkand'ı, Buhara'yı yönetme savaşına giren ve zamanla bunu başaran, bu arada da şiir yazmaya vakit ayıran, edebî, dinî sohbetlerde bulunmaya önem veren bir insandir.

Biz bu yazıda klasik geleneğe göre tanzim edilen ve tek nüshası bulunan Şiban Han Dîvânı'na farklı bir gözle bakacağız. Çalışmamızda 1998 yılında TDK tarafından yayımlanan Şiban Han Dîvânı adlı eseri kullanacağız (Karasoy, 1998). Şiban Han, son Timurlu hükümdarı Hüseyin Baykara 1507'de ölünce yeni birisinin tahta çıkmasına müsaade etmez ve Timurlu Devleti sona ererken Şibani Hanlıklarının oluşmasını sağlar. 1507 ilkbaharında Herat'ı alır ve Timur oğulları hanedanını sona erdirir. Timurlu tahtını ele geçirmek için en çok Babür Şah’la mücadeleleri olur. Kansu Gavri ve II.Bayezid ile mektuplaşır. Şah İsmail ile girdiği savaşta hayatını kaybeder (Karasoy, 1998, s.1-13).

Bir yandan savaşırken diğer yandan da edebî ve bilimsel çalışmalara katılır, devrin âlimleriyle sohbetler eder ve şiirler yazar. Türklük biliminin diline, tarihine, coğrafyasına katkılarda bulunur. Biz Şiban Han Dîvânı’ndaki coğrafyaya göz attıktan sonra bir iki şiirinde temas ettiği tarihî olaylara bakacağız. Burada Şiban Han'ın eserinde karşılaştı̆̆ımız dilbilgisi özellikleri üzerinde durmayacağız. Zaten 1998'deki yayınımızda bu konu yeterince işlenmiş olduğundan burada tekrarlamayı gerekli bulmuyoruz. Şiban Han, Cengiz soyundan olmakla övünen ve Sünnilik için çalışan bir kahramandır. Bunu şiirlerinin birçok yerinde dile getirir. Cengiz’in soyundan olduğunu ve Timurlulara karşı açtığı savaşı anlattığı beyitleri dikkate değerdir. Örnek olarak 209. şiirindeki

eger devlet çerāğını yarutsam hiç tanj irmes

ki öçken Çingizi şem 'i bilinj bigler yanar mindin

min ol șubḥ-ı șa 'ādet-min ki Çingiz kökidin tog̉dum

kaçan kim tipresem yil tig Timür şem i öçer mindin 


\section{0. şiirindeki;}

Şibān yalgan dimes kim Hak anı șāhib-ḳırān ḳıldı

Hasebde Tinjrige kul-min nesebde Çingizidür-min

beyit ise gayet açıtır. 206. şiirdeki beyitte İslam ile Cengiz töresini birleştirdiğini anlatır:

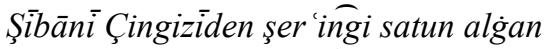

yolunjda cānın Birgen İslām ḳılıçı min-min

Yukarıda ismini saydığımız hükümdarlar içerisinde Şiban Han'ın en çok Babür Şah ile ilişkisi olmuştur. Atalarının devletine sahip çıkmaya çalışan, babasının dostları tarafından bile siyasi istikbal için yalnız bırakılan, ömrü çilelerle, mücadelelerle geçen Babür, bu dönemi ünlü eseri Vekâyi'nin birçok yerinde anlatır. Samimî tespitlerde bulunur. Dünya hatıra edebiyatının önde gelen eserlerinden olan Vekâyi bugün bile alınacak derslerle dolu bilgilere sahiptir. Reşit Rahmeti Arat'ın TTK yayınları arasında çıkan eseri hâlâ değerinden hiçbir şey kaybetmemiş bir yadigâr olarak karşımızda durmaktadır. Şiban Han ile Babür arasındaki mücadele o kadar etkilidir ki romanlara ve filmlere konu olmuştur. Özbek yazar Pirim Kadir(ov) tarafından yazılan, Türkiye Türkçesine ilk baskısı "Yıldızlı Geceler (Babür)"; genişletilmiş ikinci baskısı "Son Timurlu, Babür ve Oğullarının Romanı" adıyla aktarılan roman buna iyi bir örnektir.

Kuzeyden merkezî Asya'ya inen Şiban Han, şiirlerinde bu bölgenin coğrafyasını bize hatırlatır. Türkistan, Yesi, Buhara, Ürgenç, Herat, Horasan, Bedahşan, Semerkand, Tebriz, Karşı, Belh, Kaşgar, Rey, Hazar...gibi şehirlerin; Kara-Köl, Kızılsu, Kökçe-su, İdil, Gürgan, Ceyhun...gibi ırmak ve göllerin; Kök-saray, Künbez-i Kabus, Bâğ-1 Nev gibi o dönemin önde gelen mimarî oluşumların adlarını onun şiirlerinde görürüz.

Şiban Han, Doğu/İslam kültürüne de hâkimdir. Şiirlerinde Hz.Muhammed, Hz.Ebubekir, Hz.Ömer, Hz.Osman, Hz.Ali gibi İslamın ilk isimlerini yad ederken aynı anda Hz.İbrahim, Hz.Süleyman, Hz.İsa, Hz.Yusuf gibi peygamberleri; Leyla, Mecnun, Şirin, Vamık gibi edebî kahramanları; Hoca Ahmed Yesevî, Seyyid Nesimi, Hafız Buhari, Hoca Hüsameddin, Şeyh Burhaneddin Kılıç, Molla Mahmud, Mevlânâ Hüseyn-i Harezmi, Pir Hafız, Ali Şir Nevayî, Sadi, Benâyî gibi tasavvuf ve şiir dünyasının isimlerini bulmak mümkündür. Emir Timur'un Yesevi külliyesini onardığını biliyoruz. Şiban Han da Hoca Ahmed Yesevi'ye bağlı, onu örnek alan, şiirlerini örnek alıp benzerlerini yazan bir şairdir (Karasoy, 2009, s. 242-254). Hatta Çağataycanın en saygın ve verimli şairi Nevayi’ye nazireleri de vardır (Karasoy, 19921993, s.53-60).

Şiban Han gerek kendisinden gerekse yanındakilerden bahsederken Çingiz, nesl-i Timür, Türk, Özbek, Urus, Acem, Arap, Moğol gibi etnik adları kullanır. Fıkıh 
bilginleriyle tartışabilecek kadar İslami altyapısı olan Şiban Han'ın şiirlerinde Allah, Bârî, Cebbar, Çalap, Dâdâr, Hak, Hayy u Ahad, Huda, Huday, İlâh, İzi, İzid, Kerimizü’l-celal, Rab ve Yezdan gibi kullandığı Tanrı adları da dikkate değerdir. Şiban Han'da Tanrı kelimesi Tinjri şeklindedir ve en çok kullanılan addır.

Şiirlerinde Şâh-Baht, Şâh-Baht Han, Şiban, Şibânî mahlaslarını kullanan Şiban Han, söz dağarcığında umun, sumun gibi Moğolca kelimelerin yanı sıra Moğolcadan bozularak geçen veya ses değişikliğine uğrayan, öteki şairlerce az kullanılan bazı kelimelere de yer verir: çağdavul/çengdavul, alban, avulcay, avlak, ayalgu, badır/bahadır, bolum bolalay, çüçüg, çırmaşuk, içürgü, eymen-gibi. Bir iki eserde gördüğümüz nadir körke-bay kelimesi de Şiban Han'ın söz dağarcığındadır. Orhun Yazıtlarından beri bildiğimiz "çıgay" da bunlardandır. Şiban Han Dîvânı’nda mensur bölüm az da olsa vardır. Bu bölümlerden birisi de secilerle ve kafiyelerle bezenmiş bir yazı çeşidi olarak Murassa-nâme örneği vermesidir. Sevdiğine seslendiği şu satırlar ne kadar da edebîdir: '. ... ay mininj könjlümninj sulțānı ve sulțān-1 'sşḳımnınj şāhbāzı ve ay Barlas mihribānı taḳı mininj fikrim deryāsınınj dürr-i yetimi ve hayālım gencininj la'l ve yāḳūtı ve taḳı mürvārid-i cevāhir zỉbāsı ve ay gül-çehreler būstānınınj perīsi" (Karasoy, 1998, s.256).

Çağataycada d sesi ile başlayan kelime sayısı sınırlıdır. Ancak Şiban Han'da bunlardan da örnekler vardır: dagı/dahı, dalbay, darı-, degül, derdür, di-, dig, dola-, dudak, dur-. Babürnâme'de de sıkça gördüğümüz Bağ-1 Nev, Barlas, Baki Tarhan, Sultan Ahmed Tenbel, Benâyî gibi tarihî isimlere Şiban Han da yer verir. Bir çatışmada Babür taraftarlarınca kendi beylerinden Seyid Cafer Hoca'nın öldürülüşünü andığ 309 . şiirdeki şu beyit birçok hususu açıklar mahiyettedir.

Ca fer bigi seyidni öltürdi bu kāfirler

nesl-i Timürni kör kim boldl Yezíd haylı

Şiban Han bir taraftan Timurlulardan devlet yönetimini almak isterken, diğer taraftan da Şah İsmail'in yayılmacılı̆̆ını durdurmak zorundadır. Şiban Han 16. yüzyılın ilk yıllarından itibaren bölgeye hâkim olmaya başlar. Timurlu devletini tamamen ele geçirmeye çalışırken Şah İsmail ile de uğraşır. Timurlu torunlarını mezhebini değiștirmekle, Şiilik ile suçlar. Gerçekten de Babür'ün iktidarını kaybetmemek, devletini tekrar ele geçirebilmek için Şah İsmail ile ciddi ilişkileri vardır. Şiban Han bu durumu Divanı’nda şiirlerine serpiştirilmiş olarak anlatır. Bu duruma 22. şiirindeki

leşker-i İslämnı çiksem kızıl börk üstine

bolgusı yāver Medine kişverindin şol ḩabib

min ḳllı̧̧nı şer 'üçün çaptım Hudāy āgāhdur

likk bilmesler mun kāạdi bile şeyh ü hațīb

beyitlerinde değinir. Şiban Han'ın 139. şiirinde başka tespitleri de görürüz. 
uşbu yaz faslında azm-i Esterābād eyledük

'adl u dād ile bu ilni asru ābād eyledük

bu Timür og்lanları tagyìr kıldı mezhebin

kim ḳzıl börk dinige kirdise ber-bād eyledük

asru bì-inșāflardın kayguluk irdi bu il

merḥamet birle bu ilninj könglininj şād eyledük

Hak Ta 'ālanınj yolıda ol kadar kim birdi dest

Çapıban İslām tīğın ilni irşād eyledük

çün şeri'at yolıda koyduk kadem ihlāṣ ile

barça ālemni şeri' at birle münkad eyledük

Künbez-i Kābūs ile yaylap uşol Gürgān suyın

Kim ḳızl börk cehtidin biz azm-i Bağdād eyledük

Bu Şibānì bu țavāyif biglerini kavlaban

zulm ü cevrin köteriben ilge köp dād eyledük

Babür'ün hatıralarını yazdığı ve "Vekâyi: Babur'un Hâtıratı" adıyla TTK tarafından yayımlanan eserin önsözünü ve tarihî özetini Y. Hikmet Bayur yazmıştır. Şiban Han 1501 yılı yazında Semerkant'ı alır. Şiban Han Divanı ve Babür'ün Hatıratı'nda bu olaya değinilir. Babür Semerkant'ın elinden çıkışını şu şekilde anlatır. 'Muhasara müddeti uzadı. Zahîre ve erzak, imdat ve yardım hiçbir taraftan gelmedi. Asker ve ahali ümitsizliğe düşerek, birer-ikişer kurganı bırakıp, kaçmağa başladılar. Şaybak Han Kurgan halkının âcizliğini anlayarak, gelip Gâr-i Âşıkan civarına indi. Ben de Şaybak Han'ın karşısına, Kûy-i Pâyân'da bulunan Melik Muhammed Mirza'nın evlerine geldim. O günlerde, Uzun Hasan'ın oğlu Hoca Hüseyin, on-on beş adamı ile birlikte gelip, kurgana girdi. Yukarıda zikredildiği gibi, o, Cihangir Mirza'nın düşman olmasına ve bizim Semerkand'dan çıkmamıza da sebep olmuştu. $\mathrm{Bu}$ giriş, çok cesurâne bir giriş idi. Asker ve şehir halkının darlık ve sıkıntısı arttı. Yakın ve mûteber adamlarımız da, duvardan atlayarak kaçmağa başladı. Bey ve nâmdarlardan ve eski emekdarlarımızdan bir Veys Şeyh ile Veys Lâgarî vardı; onlar da kaçtılar. Ben ve yanımda bulunanlar hepimiz me’yus olduk. Hiçbir taraftan ümit kalmadı. Erzak ve zahîre de azdı; olan kadarı da tükendi. Hiçbir taraftan erzak ve zahîre gelmedi. Bu esnada Şaybak Han barış sözünü ortaya attı. Eğer her hangi bir taraftan ümit olsa veya zahîre bulunsa idi, sulh sözüne kim kulak asardı. Zarûret hâsıl oldu ve sulha benzer bir şey yapıp, gece yarısı, Şeyhzâde kapısından çıkıldı. Vâlidem Hanım'ı beraber götürdüm. Ondan başka iki kadın çıktı; biri Biçke Halife, diğeri Minglig Kökeltaş idi. Büyük kız kardeşim Hanzâde Begim bu çıkışta Şaybak Han'ın eline düştü. Karanlık gecede Soğd'un büyük arıklarından çabalanarak, 
yolumuzu kaybedip, bin meşakkatle sabahleyin Hoca Didar'dan geçip sünnet vaktinde Karpuk dağına tırmandık." (Arat, 1987, s. 99). Burada anlatılanlara Şiban Han, divanının iki yerinde şöyle değinir. Semerkand'da kıtlık olduğunu:

"Basa Semerḳand'da bir batman bug̉day minj altunġa yitti Bābur Mirzā ḳarındaşın birip mürüvvet tiledi irse şefā'at ḳılıp yiberdim.” cümleleriyle anlatır (Karasoy, 1998, s. 214).

Timur devri emirlerinden Şâh Melik'in torunu Hârezm valisi Nur Said Bey'in oğlu Muhammed Salih de dönemin şairlerindendir. Önceleri Hüseyin Baykara'nın yanında iken, sonradan Şiban Han'ın hizmetine girer ve onun "Emirü'l-ulemâ ve melikü'ş-şuarâ"sı olur. Manzum bir tarih olan Şibani-nâme adlı eseri Şiban Han devrine ışı tutması bakımından önemlidir (Eraslan, 1986, s. 9). Muhammed Salih, Semerkand'ın kuşatılması ve bu esnada halkın durumunu Şibanî-name'nin Budapeşte nüshasında şöyle anlatır:

sonjlça kilip han aldı kapay

Semerkandninj şehrini altı ay

takı hacelergia nasihat kılip

yayuşmadl kurgianga firșat killp

tutup pendni birmediler cevāb

ulusnunjki ạ̣vāli boldı harāo

minj altunga yitişti batman azuk

atı bar anınj takı özi yok

tapllmas idi isteben un и tuz

yimişleri küncārādın yok üz

nige sözge biz kirmedük didiler

biri birininj itlerin yidiler

(Evirgen, 2019, s.16-17)

Muhammed Salih, Șibanî-name'nin Viyana nüshasında da halkın Babür'e gelerek şehri terk etmesini istediklerinden bahsetmiş, kız kardeşinin Şiban Han ile evlenmesi hususunu ise bir beyitle geçiştirmiştir:

imdi tedbir budur kim mìrzā

kılmayın şehr ili birle ġavgā

han bile sulh sözin ayıtkay

fitne vü kin başıdın kayıtḳay

hanġa hemşiresini 'akd itgey

ol barı han kademiga yitgey 
şehrdin kaçkay ü kitkey

şeyhü'l-islām hem anja hem-pā

(Kocasavaş, 2003, s. 331)

$\mathrm{Bu}$ dizeler bize Babür’ün dediği gibi, kız kardeşinin Şiban Hanın eline düşmediğini, kurtulmak için kız kardeşini verdiğini gösteriyor.

Şiban Han daha sonra Babür'le olan yazışmasını da anlatır:

'Basa Bābur Mirzānınj ilçisi kildi ḩațțını ḳarındaşıg̉a körsettim irse bir derdlig āhĩ ḳıldı ḳayda barg̉a-sin ḳayda yir tapḳa-sin didi irse mining hem könglüme Maḥmūd Bahādırnınj yaġığa tüşkendeki firāḳı otı içimde ḳayra kildi micmer tig köyüp közüm yaşı birle bu gazelni aytıp yiberdim taḳı sulțān cevāb aytıp yiberdi" (Karasoy, 1998, s. 253).

Bu olayı Babür'ün teyzesinin oğlu olan ve Tarih-i Reşidî̀yi yazan Mirza Mehmet Haydar Duğlat, Babür'ün ablası Hanzade’yi Şaybak’a vererek bir anlaşma yaptı̆̆ı ve Semerkant'tan çıktığı şeklinde yazar. Babür'ün ölümünden 50 yıl ve bu evlenme işinden 80 yıl kadar sonra Babür'ün kızı Gülbeden, Humayunname’de (s. 3a-b) Semerkant'ta kuşatılmış olan babasının çok güç ve acı durumunu anlattıktan sonra şöyle der: 'Bu sırada Şahı Bey Han (Şibani) haber yollar ki eğer kızkardeşiniz Hanzade Beyim'i benimle evlendirirseniz aramızda sulh ve birlik bağları olur. Sonda zaruret oldu, Hanzade Beyim işbu Hanla evlendirildi ve kendisi çıktı.” (Arat, 1987, s.081).

Babür hatıralarını büyük bir samimiyetle yazmıştır. Eserinin hiçbir yerinde isteyerek yalan söylememiştir. Burada önemli olan böylesine bir tarihî olayın Şiban Han’ın divanında da kısa da olsa anlatılmış, değinilmiş olmasıdır. Şiirlerinin arasına sıkıştırdığı hacimce çok az olan mensur bölümlerde iki büyük şairin birbirini doğruladığına tanık oluyoruz.

Eserin Babür-Şiban Han ve Şah İsmail arasındaki ilişkilerin anlatıldı̆̆ bölümünden bir parça şöyledir: 'İsmail bir yandan Özbeklerle savaşması için Ahmet Bey Sufioğlu ve Şahruh Bey Afşar’ın komutanlığında bir ordu yollar. Bu yardım bazı tarihçilere göre iki defada, bir kere Hisar alınmadan Han Mirza ile birlikte ve bir defa da orası alındıktan sonra yukarda sözü geçen iki beyle yollanılmıştır. Bu yardımın karşılığı, Babur'un Şiiliği kabul etmesi, hutbe ve paralarında Şii imamlarının ve İsmail'in adlarını sayması yani İsmail'e tâbi olmasıdır. Bu yardımla Babur önce Hisar'1, sonra Buhara, Semerkant (recep 917, ilkteşrin 1511) ve Taşkent'i alacak ve bu yerler ve halkça da sevilmesi yüzünden ordusu 60.000 kişiye kadar çıkacaktır. Yine o sıralarda Fergana da, en çok Moğollar tarafından Özbeklerin elinden alınacaktır. Bu işe girişildiği anda Babur'un gücünün ne olduğunu göstermesi dolayısıyla Tarihi Reşidînnin verdiği şu bilgiler önemlidir...” (Arat, 1987, s.101). 
Şiban Han'ın 139. şiirinin 2. beyti ile Bayur'un yorumunun örtüşmesine rağmen verilen tarihlerin uyuşmadığ 1 görülmektedir. Şiban Han, Şah İsmail ile yaptığı savaştan sonra 2 Aralık 1510 'da ölmüştür. Y. Hikmet Bayur'un anlattığ 1511'den sonradır. Bu da bize daha Şiban Han'ın sağlığında Babür ile Şah İsmail arasında bazı görüşmelerin yapıldığını belgelemesi açısından önemlidir. Kendisini Sünnilik için çalışan bir kahraman olarak gören ve "zamanın imamı ve rahman olan Allah'ın halifesi” ilan eden, Şah İsmail'i Sünniliğe davet eden Şiban Han'ın olacakları önceden gördügünü tahmin edebiliriz. Şiban Han Divanı'nda değinmek istediğimiz ikinci tarihî olay Kazan Hanı ile ilgilidir. Kazan Hanı Muhammed Emin Han'ın 1505 yılında Rusları mağlup ettiğini öğrenince memnuniyetinin ifadesi olarak yazılan bir rubai vardır. 16. yüzyılın ilk yılları Şiban Han için altın yıllardır. Semerkand dâhil bölgenin hemen hemen tamamı Şiban Han'ın yönetimi altındadır. Söz konusu rubaide dikkatimizi çeken "Oğlum" ifadesidir. Artık Şiban Han bölgenin en büyük gücü olarak üst perdeden konuşmaktadır. Bu rubainin bize ikinci hatırlatması Türk yurtlarının birbirlerinden haberdar oldukları gerçeğidir.

\section{İslām başınja tāc-ı tärek bolsun \\ Yārnj tün ü kün Tinjri tebārek bolsun \\ İşittim Urus käfirini kırmış-sin \\ Oğlum sanja ġäzilık mübārek bolsun}

Bilindiği gibi bu şiirin yazılışından bir müddet sonra 1552'de Kazan yüzyıllar boyu sürecek olan Rus istilasına uğrayacaktır.

\section{Sonuç}

Şiban Han, İslâmi ilimleri, tasavvuf nazariyelerini bilen, İran edebiyatına vâkıf olan, güzel sanatlardan, musikiden anlayan sanatkâr ruhlu bir hükümdardır. Askerî ve siyasi işlerinin arasında kaleme aldığ 1 eseri gerek kültürel yanı, gerek dil yapısı gerekse ileriye dönük tarihî öngörüleriyle ayrıca ele alınması gereken bir içeriğe sahiptir. Onun şiirleri, bizim kısaca değindiğimiz konular dışında ağız kelimelerinden eskicil kelimelere, divan şiirinin güzelliklerine, tarihî olaylara göndermelerle Türk dünyasını hatırlatan Türkistan, Türk, Urus, Çingiz, Timür, kızıl börk, tarhan, Yağma, Tatar, Sultan Sençer gibi daha birçok ismi görebilmemize imkân sağlıyor. $\mathrm{Bu}$ da bize şairlerin divanlarına başka gözlerle de bakmamız gerektiğini hatırlatıyor. 


\section{Kaynaklar}

Arat, R. R. (1987). Vekayi Babur'un hâtıratı (2. baskı). TTK Yayınları.

Eraslan, K. (1986). Çağatay şiiri. Türk Dili Türk Şiiri Özel Sayısı-II (Divan Şiiri), (415-416-417), 564-718.

Evirgen, A. E. (2019). Şibani-name'nin Budapeşte Nüshası (Metin-İncelemeDizin) [Yayımlanmamış Doktora tezi]. Gazi Üniversitesi.

Karasoy, Y. (1992-1993). Şiban Han divânı'nda Nevâyîye nazireler. SÜ FenEdebiyat Fakültesi Dergisi, (7-8), 53-60.

Karasoy, Y. (1998). Şiban han dîvânı. TDK Yayınları.

Karasoy, Y. (2009). Şiban Han divanı'nda dinî unsurlar ve Hoca Ahmed Yesevî izleri, Ahmet Yesevi Uluslararası Türk-Kazak Üniversitesi III. Uluslararası Türkoloji Kongresi (s. 242-254).

Kocasavaş, Y. (2003). Şeybanî-nâme giriş-tıpkıbasım-metin-tercüme. Çantay Yayınları. 